\title{
Severe Cardiac Valve Regurgitation
}

National Cancer Institute

\section{Source}

National Cancer Institute. Severe Cardiac Valve Regurgitation. NCI Thesaurus. Code C100012.

Evidence of severe retrog rade blood flow through the valve(s) of the heart. (ACC) 